\title{
Gestão de resíduos na produção e atenção à saúde animal
}

\section{Waste management in production and animal health services}

\section{Resumo}

Os resíduos têm se tornado um problema mundial quanto ao prejuízo e poluição do meio ambiente, pois além do impacto e comprometimento dos recursos naturais, eles trazem grandes e graves consequências à saúde humana e dos animais. A legislação relativa ao descarte em vigor no Brasil é genérica e aplica-se também aos resíduos gerados em serviços veterinários, porém, devido à diversidade de espécies animais e atividades distintas, ela não é suficientemente clara. O presente trabalho discorre sobre os principais resíduos gerados na produção animal em geral e, em especial, sobre os resíduos de atendimento à saúde animal, organizando as informações para o cumprimento das atuais normas, com práticas adequadas de gestão, manejo e destinação ambientalmente adequada dos resíduos gerados na área animal. Como resultados foram produzidos o Plano de Gerenciamento de Resíduos de Serviços de Saúde Animal (PGRSSA) e um adesivo com os principais resíduos gerados nas atividades da área animal. Concluiu-se também que, pela complexidade do tema, há a urgente necessidade de legislação específica para a área animal, dado o distanciamento entre a teoria e o que é realizado na prática.

\section{Abstract}

Waste disposal has become a worldwide problem in terms of environment damage and pollution. If they are disposed without any treatment, besides the impact and commitment of natural resources there are also great and serious consequences to human and animal health. The Brazilian legislation is generic and can be applied to waste generated in veterinary services, but due to the diversity of animal species and their distinct activities, it is not enough clear. The present paper discuss the main residues generated in animal production in general, with particular interest to animal health care waste and rationalize the information to be attended the current standards with appropriate practices of control, management and environmental adequate disposal of the waste generated in animal area. As results it were produced the Waste Management Plan for Animal Health Services, and stickers with the main residues generated in the activities of the animal area. It was also concluded that there are an urgent need for a specific legislation for the animal area, since there is a gap between theory and what is accomplished in current practice. 
Rua Santa Helena, 1967, Casa 53 Jd. Estoril, Marília, São Paulo/SP. CEP: 17514-410

囚elmapolegato@hotmail.com

\section{Palavras-chave}

Resíduos de serviços de saúde animal. Meio ambiente. Impactos ambientais.

Resíduos na produção animal.

\section{Keywords}

Residues of animal health services.

Environment. Environmental impacts.

Residues in animal production.

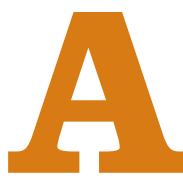

partir do século XVIII, o aumento da população mundial, combinado às mudanças comportamentais promovidas pela Revolução Industrial e os novos padrões de consumo dela decorrentes elevaram geração de resíduos a patamares jamais atingidos, o que compromete a disponibilidade de recursos naturais do planeta. A exploração insustentável destes recursos é considerada hoje um problema que ameaça o equilíbrio ecológico mundial, pondo em risco o bem-estar da população.

Neste sentido, o século XX foi marcado não só pelo alto nível das ações antrópicas como pela degradação ambiental. Um dos fatores preocupantes dessa degradação é a poluição, uma mudança indesejável no ambiente, decorrente da introdução de concentrações exageradas de substâncias prejudiciais ou perigosas resultantes de práticas humanas, tais como a geração indiscriminada de resíduos nas atividades industriais, domiciliares, públicas, da construção civil, dos serviços de saúde e agrícolas. Quando descartados e acumulados de forma inadequada no meio ambiente, tais resíduos podem afetar a saúde humana, animal e ambiental, além de representarem um desperdício de matéria-prima. 
A poluição acabam por impactar a qualidade da água, do ar, do solo e dos alimentos, trazendo consigo uma série de riscos. Portanto, se descartados sem qualquer tratamento, os resíduos se tornam um problema mundial quanto ao prejuízo e poluição do meio ambiente, podendo afetar o solo, a água e o ar.

A poluição do solo pode alterar as suas características físico-químicas, o que representa uma séria ameaça à saúde pública, pois o ambiente passa a ser propício ao desenvolvimento de agentes transmissores de doenças. A poluição da água pode alterar as características do ambiente aquático, devido à percolação do líquido gerado pela decomposição da matéria orgânica presente no lixo, associado às águas pluviais e nascentes existentes nos locais de descarga dos resíduos. A poluição do ar pode provocar a formação de gases naturais na massa de lixo pela decomposição dos resíduos com e sem a presença de oxigênio, originando riscos de migração de gás, explosões e até doenças respiratórias quando há contato direto com tais resíduos.

Os resíduos de serviços de saúde (RSS) estão inseridos nesta problemática, não de forma quantitativa, e sim devido ao potencial de risco que podem oferecer tanto para a saúde quanto para o meio ambiente, por conta de seus componentes químicos, biológicos e radioativos (BRASIL, 2006). Os RSS resultam do atendimento à saúde humana ou animal e são gerados em hospitais, clínicas, laboratórios, farmácias, serviços de assistência domiciliar, estabelecimentos de ensino e pesquisa na área de saúde, centros de controle de zoonoses e distribuidoras de produtos farmacêuticos, dentre outros (BRASIL, 2004, 2018b).

Entre as fontes de degradação ambiental, os resíduos sólidos gerados na área da saúde apresentam grande periculosidade quando inadequadamente gerenciados (CORREA et al., 2005). Assim também, na produção animal, além dos resíduos de medicamentos, há de se considerar os resíduos das atividades agrossilvipastoris, que podem ser classificados como orgânicos e inorgânicos (FUNDAÇÃO DE ESTUDO E PESQUISA VETERINÁRIA E ZOOTECNIA, 2013).

Essa problemática vem sendo objeto de preocupação de órgãos de saúde e ambientais, prefeituras, técnicos e pesquisadores da área devido aos vários fatores que têm contribuído para o aumento da geração dos RSS, como o contínuo incremento da complexidade da atenção médica e o uso crescente de material descartável, além do aumento da população, que necessita de mais serviços de saúde. Assim também ocorre na área animal, onde se observa o número crescente de animais de estimação e a busca por seu bem-estar por parte dos tutores/ proprietários, o que aumenta a demanda dos procedimentos veterinários para fins curativos, preventivos e de produção.

Estima-se, portanto, que a geração de RSS deve ainda aumentar na área animal (SILVA, 2014), exigindo a ampliação dos conhecimentos sobre correto gerenciamento tanto em estabelecimentos veterinários como envolvidos com a produção animal.

Embora a legislação em vigor no Brasil também seja aplicada aos resíduos gerados em serviços veterinários, frente à diversidade de espécies animais e atividades distintas ela não é suficientemente clara. O presente artigo tem como objetivo fornecer subsídios aos médicos-veterinários, zootecnistas, produtores e demais técnicos que atuam na área animal para a correta interpretação da legislação ambiental e sanitária brasileira no tocante aos resíduos gerados tanto na produção como no atendimento a saúde animal, para que eles possam organizar as informações existentes e atender as atuais regras de gestão, manejo e destinação ambiental dos resíduos gerados na área animal.

\section{Gestão dos resíduos e meio ambiente}

Considerando que a gestão adequada dos resíduos garante a sustentabilidade para a continuidade das atividades, torna-se importante conhecer a legislação vigente, relativa à gestão dos resíduos gerados a partir da atividade desenvolvida, segundo o ramo e natureza do estabelecimento ou da prestação de serviços, no manejo e na destinação ambiental dos resíduos produzidos, bem como os fundamentos técnicos necessários para elaboração e gestão do Plano de Gerenciamento de Resíduos (PGR).

O gerenciamento dos resíduos é um conjunto de procedimentos de gestão, planejados e implementados a partir de bases científicas, técnicas e normativas legais que objetivam minimizar sua produção e encaminhar os resíduos gerados de modo seguro, visando à proteção dos trabalhadores, à preservação da saúde pública e do ambiente, com diretrizes de manejo que devem ser adotadas desde a segregação até a destinação final (SISSINO; MOREIRA, 2005).

\section{Legislação sobre resíduos de serviços de saúde}

A Resolução de Diretoria Colegiada da Agência Nacional de Vigilância Sanitária (Anvisa) n 306/04 (BRASIL, 2004) e a Resolução do Conselho Nacional do Meio-Ambiente (Conama) n ${ }^{\circ}$ 358/05 (BRASIL, 2005) abordam o gerenciamento dos RSS em todas as suas etapas. Elas dispõem, respectivamente, sobre o gerenciamento interno e externo dos RSS, destacando a 
importância da segregação na fonte, da orientação para os resíduos que necessitam de tratamento e da solução diferenciada para a disposição final, desde que aprovada pelos órgãos de meio ambiente, limpeza urbana e saúde.

Em 28 de março de 2018, foi publicada a RDC Anvisa $\mathrm{n}^{\circ} 222$ (BRASIL, 2018b), que regulamenta as Boas Práticas de Gerenciamento de Resíduos de Serviços de Saúde. A referida resolução passará a vigorar a partir de 25 de setembro de 2018, revogando a Resolução Anvisa/ RDC 306/04 (BRASIL, 2004).

A RDC n 222/2018 (BRASIL, 2018b) traz poucas alterações em comparação à RDC n ${ }^{\circ} 306 / 04$. Trata-se de uma atualização objetiva e clara do regulamento técnico para o gerenciamento de RSS (BRASIL, 2004), dispondo sobre os requisitos de boas práticas no gerenciamento e manejo de tais resíduos em todas as suas etapas, dando maior praticidade e segurança às ações que devem ser realizadas.

Portanto, considerando a atualização, a RDC Anvisa $n^{\circ} 222 / 2018$ (BRASIL, 2018b) e a Resolução Conama $\mathrm{n}^{\circ} 358 / 05$ (BRASIL, 2005) definem a conduta dos diferentes agentes da cadeia de responsabilidades pelos RSS. Elas mostram ainda a mudança de paradigma no trato dos RSS, fundamentada na análise dos riscos envolvidos, em que a prevenção passa a ser o eixo principal, e o tratamento é visto como alternativa para a destinação adequada dos resíduos com potencial de contaminação, exigindo que recebam um manejo específico, desde a sua geração até a disposição final, e definindo competências e responsabilidades para tal.

É importante ressaltar que a Lei Federal no 12.305/10 (BRASIL, 2010), que dispõe sobre a Política Nacional de Resíduos Sólidos (PNRS), também contempla os RSS, estabelecendo normas para seus geradores. As regulamentações específicas são:

- RDC Anvisa n 306/04: regulamento técnico para o gerenciamento de RSS (estará revogada a partir de 25 de setembro de 2018).

- RDC Anvisa $n^{\circ} 222$ de 28/18: concentra a sua regulação nas boas práticas para o controle dos processos de segregação, acondicionamento, armazenamento, transporte, tratamento e disposição final. Estabelece procedimentos operacionais em função dos riscos envolvidos e concentra seu controle na inspeção dos serviços de saúde, incluindo o atendimento em saúde animal. (Obs.: esta resolução substituirá integralmente a RDC $306 / 2004$ a partir de 25 de setembro de 2018).
- Resolução Conama n ${ }^{\circ}$ 358/05: trata do gerenciamento sob o prisma da preservação dos recursos naturais e do meio ambiente. Define a competência dos órgãos ambientais estaduais e municipais para estabelecer critérios para o licenciamento ambiental dos sistemas de tratamento e destinação final dos RSS.

- Lei Federal no 12.305/10: instituiu a PNRS, dispondo sobre seus princípios, objetivos e instrumentos, bem como sobre as diretrizes relativas à gestão integrada de resíduos sólidos, incluindo os perigosos, às responsabilidades dos geradores e do poder público e aos instrumentos econômicos aplicáveis.

Ainda no Estado de São Paulo, deve-se considerar:

- Resolução Conjunta no SS/SMS/SJDC-SP-1/04: estabelece a classificação, diretrizes básicas e regulamento técnico sobre resíduos de serviços de saúde animal (RSSA) (SÃO PAULO, 2004).

- Portaria CVS no 21/08: aprova Norma Técnica sobre Gerenciamento de Resíduos Perigosos de Medicamentos em Serviços de Saúde (SÃO PAULO, 2008).

- Manual de responsabilidade técnica e legislação: gestão de resíduos e meio ambiente (CONSELHO REGIONAL DE MEDICINA VETERINÁRIA DO ESTADO DE SÃO PAULO, 2018).

Quanto aos RSS, que por suas características necessitam de processos diferenciados em seu manejo, exigindo ou não tratamento prévio à disposição final (BRASIL, 2018b), o profissional médico-veterinário será o responsável pela elaboração, implantação e monitoramento do PGR, ou poderá contratar um serviço especializado para tal fim, definindo a forma como será realizada a coleta, segregação, acondicionamento, identificação, armazenamento, transporte e destinação final, instituindo inclusive um responsável técnico. Outro requisito importante é o treinamento contínuo de profissionais e colaboradores envolvidos com o gerenciamento dos RSS.

Caberá, de acordo com a referida resolução, a elaboração do Plano de Gerenciamento de Resíduos de Serviços de Saúde (PGRSS), obedecendo a critérios técnicos, legislação ambiental, normas de coleta e transporte dos serviços locais de limpeza urbana e outras orientações necessárias.

Cabe ao responsável técnico constituir um conjunto de procedimentos de gestão de resíduos, planejados e implementados a partir de bases científicas e técnicas, 
normativas e legais. Ele também deverá indicar os processos que serão utilizados pelo estabelecimento para a não geração ou minimização de resíduos, bem como de todos os passos para a sua segregação na fonte, acondicionamento, coleta, armazenamento, transporte, reuso, reciclagem, tratamento e disposição final específica (Figura 1).

A designação de profissional - com registro ativo junto ao seu conselho de classe e apresentação de Anotação de Responsabilidade Técnica (ART), Certificado de Responsabilidade Técnica ou documento similar, quando couber - para exercer a função de Responsável pela elaboração e implantação do PGRSS deverá ser estabelecida pela empresa ou instituição envolvida. É importante ressaltar que a responsabilidade do gerador perdura mesmo após a disposição final do resíduo, posto que o destinatário, ao assumir a carga, solidariza-se com o gerador e assim permanece enquanto é possível a identificação do resíduo.

Os RSS gerados por estabelecimentos de atenção individualizada caracterizam-se por uma dispersão territorial significativa, pequeno volume de geração e inexistência de processos de gestão. Nestes estabelecimentos, o PGRSS deve conter as informações necessárias para o correto gerenciamento dos resíduos, apresentadas a seguir em um passo a passo. Conforme o perfil de geração, o PGRSS pode ser elaborado de forma simplificada, com base no Plano de Gerenciamento de Resíduos de Saúde Animal (PGRSSA), que pode ser acessado no site do Conselho Regional de Medicina Veterinária $(\mathrm{CRMV}-\mathrm{SP})^{(1)}$.

O médico-veterinário, quando responsável pela elaboração, implantação e monitorização do PGRSS, seja pelo estabelecimento gerador de RSS ou pela prestação de serviços, quando no exercício de suas funções, deve:

a) estimar a quantidade dos RSS gerados por grupos, conforme a classificação do Anexo I da RDC Anvisa no 222/2018;

b) elaborar e encaminhar o PGRSS ao órgão competente com a descrição dos procedimentos de gerenciamento dos RSS quanto a sua geração, segregação, acondicionamento, identificação, coleta, armazenamento, transporte, tratamento e disposição final ambientalmente adequada;

c) estar em conformidade com as ações de proteção à saúde pública, do trabalhador e do meio ambiente; d) estar em conformidade com a regulamentação sanitária e ambiental e com as normas de coleta e transporte dos serviços locais de limpeza urbana;

e) quando aplicável, contemplar os procedimentos locais definidos pelo processo de logística reversa para os diversos RSS;

f) estar em conformidade com as rotinas e processos de higienização e limpeza vigentes no serviço gerador de RSS;

g) descrever as ações a serem adotadas em situações de emergência e acidentes decorrentes do gerenciamento dos RSS;

h) descrever as medidas preventivas e corretivas de controle integrado de vetores e pragas urbanas, incluindo a tecnologia utilizada e a periodicidade de sua implantação;

i) descrever os programas de capacitação dos funcionários desenvolvidos e implantados pelo serviço gerador, abrangendo todas as unidades geradoras de RSS e o setor de limpeza e conservação;

j) apresentar documento comprobatório da capacitação e treinamento dos funcionários envolvidos na prestação de serviço de limpeza e conservação, próprios ou terceiros, de todas as unidades geradoras;

k) apresentar cópia do contrato de prestação de serviços e da licença ambiental das empresas prestadoras de serviços para a destinação dos RSS;

1) apresentar documento comprobatório de operação de venda ou de doação dos RSS destinados à recuperação, à reciclagem, à compostagem e à logística reversa;

m) estar ciente de que o PGRSS é uma atividade interdisciplinar, ou seja, que deverá ser elaborado, implantado e acompanhado por uma equipe multidisciplinar;

n) certificar-se de que a cópia do PGRSS esteja disponível para consulta dos funcionários, dos pacientes e do público em geral, ou quando solicitada por autoridade sanitária ou ambiental competente;

(1) <www.crmvsp.gov.br> 
o) ter conhecimento sobre os potenciais riscos químicos, físicos, biológicos e radioativos à saúde e ao meio ambiente decorrentes do mau gerenciamento e disposição final de RSS;

p) ter conhecimentos em biossegurança;

q) nos resíduos onde predominam os riscos biológicos, deve-se considerar o conceito de cadeia de transmissibilidade de doenças, que envolve características do agente agressor, tais como capacidade de sobrevivência, virulência, concentração e resistência, da porta de entrada do agente às condições de defesas naturais do receptor (BRASIL, 2006);

r) orientar:

1) o profissional competente na elaboração de projetos de construção de espaços físicos destinados ao depósito e acondicionamento temporário de RSS;

2) quanto ao programa integrado de controle de vetores e roedores;

3) a coleta seletiva no estabelecimento gerador de RSS, priorizando a identificação e a segregação na origem;

4) a execução dos trabalhos, visando a não geração, minimização, reutilização e reciclagem dos RSS;

5) treinar equipes de trabalho de estabelecimentos geradores de RSS, envolvendo o quadro de terceirizados, os setores de higienização e limpeza, engenharia de segurança e medicina do trabalho, em consonância com a legislação de saúde e ambiental vigente;

6) definir os tipos de equipamento de proteção individual (EPI) a serem utilizados pelos funcionários ligados ao setor de higiene, bem como a simbologia padronizada dos diversos equipamentos, materiais e compartimentos relacionados aos RSS;

7) garantir que os recipientes, containers e locais de armazenamento temporário dos RSS sejam mantidos limpos e desinfetados com periodicidade e produtos adequados; s) adotar medidas de controle de efluentes líquidos com risco de contaminação ambiental oriundos dos RSS;

t) permitir a utilização somente de produtos aprovados pelos ministérios da Saúde e Agricultura, e orientar o proprietário da empresa sobre as consequências do uso de produtos não aprovados;

u) conhecer tecnologias de neutralização de RSS;

v) conhecer os principais microrganismos responsáveis pelas contaminações veiculadas pelos RSS;

w) manter registro dos dados qualitativos e quantitativos relativos ao RSS para monitoramento e atualização do PGRSS;

x) manter registro de acidentes de trabalho envolvendo RSS;

y) ter conhecimento dos aspectos técnicos e legais a que estão sujeitos os estabelecimentos geradores de RSS, especialmente quanto aos regulamentos e normas que envolvam a atividade e a legislação da Secretaria de Saúde/Vigilância Sanitária e órgãos de meio ambiente nas três esferas (federal, estadual e municipal).

Os RSS necessitam de atenção especial em todas as suas fases de manejo em decorrência dos imediatos e graves riscos que podem oferecer por conta de seus componentes químicos, biológicos e radioativos. Os componentes químicos são representados por substâncias ou preparados químicos: tóxicos, corrosivos, inflamáveis, reativos, pesticidas e solventes, entre outros. Os biológicos são componentes que contêm agentes patogênicos, e os radioativos são os que contêm materiais emissores de radiação, utilizados em procedimentos de diagnóstico e terapia (BRASIL, 2006).

Os riscos potenciais dos resíduos de saúde estão concentrados em dois fatores: no impacto à saúde ocupacional daqueles que os manipulam na assistência médica ou médico-veterinária e das pessoas ligadas ao setor de limpeza, e ainda no impacto ao meio ambiente, em razão da destinação inadequada.

Os riscos do manejo dos RSS estão vinculados aos acidentes devido às falhas de acondicionamento e segregação dos perfurocortantes sem proteção adequada. Quanto aos riscos ao meio ambiente, destacam-se os riscos relacionados aos catadores por materiais cortantes ou perfurocortantes, pela ingestão de alimentos contaminados e a poluição do ar pela realização de incineração descontrolada (BRASIL, 2006). 


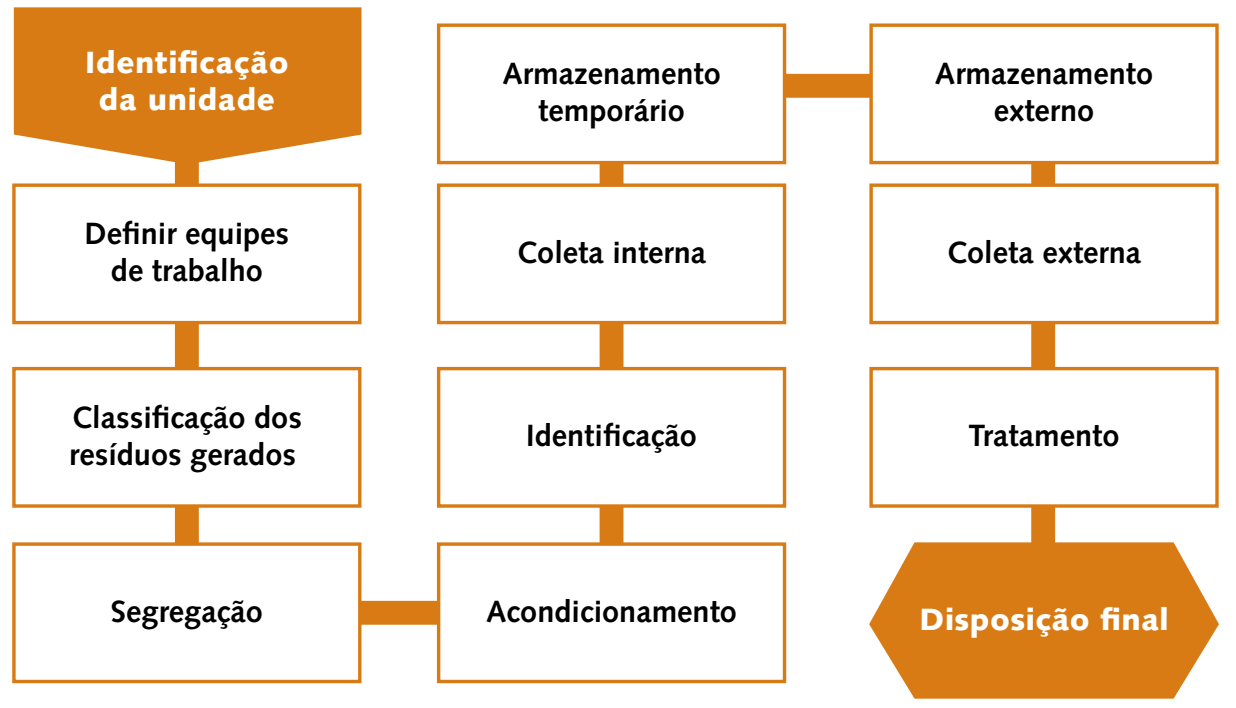

Figura 1 - Procedimentos no manejo de resíduos. Fonte: Mori (2015). ${ }^{(2)}$

\section{Passo a passo no manejo de resíduos}

\section{1) Identificação da unidade/estabelecimento}

Coletar dados de identificação do estabelecimento, como nome, razão social, endereço e outros.

\section{2) Definir equipe de trabalho}

A equipe de trabalho é formada pelos colaboradores/funcionários do estabelecimento, que deverão ser treinados para atuar no manejo de resíduos intra-estabelecimento em todas as etapas, preparando-os adequadamente para a coleta externa e observando os cuidados de segurança com o uso dos equipamentos de proteção individual e coletivo.

\section{3) Classificação dos resíduos}

Os RSS são classificados com base em suas características e riscos que podem acarretar ao meio ambiente e à saúde. De acordo com a legislação já citada, os RSS são classificados em cinco grupos: A, B, C, D e E, sendo que no Estado de São Paulo ainda deve ser cumprida a Resolução Conjunta ${ }^{\circ}$ SS/SMS/SJDC-SP-1, de 15 de julho de 2004 (SÃO PAULO, 2004), que estabelece a classificação, diretrizes básicas e regulamento técnico sobre RSSA, incluindo mais um grupo, F, conforme a Figura 2.

\section{4) Segregação}

Consiste na separação e/ou seleção dos resíduos segundo a classificação adotada e é uma das etapas mais importantes para um gerenciamento adequado. Deve ser realizada na fonte de geração e é condicionada à prévia capacitação do pessoal de serviço. Envolve todos os profissionais da instituição, pois é realizada pela pessoa que gera o resíduo no local onde ele é produzido. O principal objetivo não é apenas reduzir a quantidade de resíduos com risco biológico, mas também criar uma cultura organizacional de segurança e de não desperdício.

A segregação de RSS costuma ser um ponto crítico no processo de minimização de resíduos potencialmente infectantes, podendo trazer resultados insatisfatórios na gestão. Sem uma segregação adequada, cerca de 70 a $80 \%$ dos resíduos gerados em serviços de saúde, e que não apresentam risco inicial, acabam potencialmente contaminados (BRASIL, 2006).

\section{5) Acondicionamento}

As principais funções do acondicionamento adequado dos RSS são: isolamento dos resíduos do meio externo, evitando contaminação, e sem a possibilidade de serem acessados por vetores; identificação por meio de cores, símbolos e inscrições segundo a classe do resíduo; e manutenção dos resíduos agrupados para facilitar o seu gerenciamento, transporte e tratamento. $\mathrm{O}$ acondicionamento deve ser feito em duplo saco plástico de cor branca leitosa, com identificação do resíduo e dos riscos a ele atribuídos, ou em recipiente rígido e estanque, compatível com as características físico-químicas do resíduo ou produto a ser descartado. O recipiente rígido deverá ser identificado de forma visível com o nome do conteúdo e das suas principais características.

\footnotetext{
(2) Figura apresentada por Ana Cláudia Fiori Mori na oficina intitulada "Clínica Veterinária: Desafios e Soluções na Gestão de Resíduos de Serviços de Saúde Animal", São Paulo, 6 out. 2015.
} 
- Resíduos líquidos: acondicionar em recipientes constituídos de material compatível com o líquido armazenado, resistente, rígido e estanque, com tampa rosqueada e vedante. Devem ser identificados de acordo com as suas especificações (BRASIL, 2006).

- Resíduos sólidos: acondicionar em recipientes de material rígido, adequados para cada tipo de substância química, respeitadas as suas características físico-químicas e o seu estado físico, devendo ser identificados de acordo com suas especificações (BRASIL, 2006).

\section{6) Identificação}

A identificação permite o reconhecimento dos resíduos contidos nos sacos e recipientes, fornecendo as informações necessárias para o seu correto manejo (BRASIL, 2006).

\section{7) Transporte interno}

É a retirada e translado dos resíduos dos pontos de geração até o local destinado ao seu armazenamento temporário ou externo com a finalidade de apresentação para a coleta. $O$ transporte interno de resíduos é realizado atendendo ao roteiro e horários previamente definidos.

\section{8) Armazenamento temporário}

O resíduo ou produto a ser descartado é armazenado em recipiente rígido e estanque, compatível com suas características físico-químicas. Os recipientes deverão ser identificados de forma visível, com o nome do conteúdo e a especificação das suas principais características.

\section{9) Tratamento interno}

Consiste na aplicação de método, técnica ou processo que modifique as características do resíduo, reduzindo ou eliminando o risco de contaminação, de acidentes ocupacionais ou de danos ao meio ambiente. $\mathrm{O}$ processo de autoclavação aplicado em laboratórios para redução da carga microbiana de culturas e estoques de microrganismos está dispensado de licenciamento ambiental. A garantia da eficácia dos equipamentos utilizados mediante controles químicos e biológicos periódicos fica sob a responsabilidade dos serviços que os executarem.

\section{0) Armazenamento externo}

É a guarda dos recipientes de resíduos até a coleta externa, em ambiente exclusivo e com acesso facilitado para os veículos coletores.

\section{1) Coleta externa}

Consiste na remoção do RSS do abrigo até a unidade de disposição final, que deverá ser realizada com técnicas que garantam a preservação das condições de acondicionamento e a integridade dos trabalhadores e do meio ambiente.

\section{2) Tratamento}

É a aplicação de método, técnica ou processo que modifique as características dos riscos inerentes aos resíduos, reduzindo ou eliminando o risco de contaminação, de acidentes ocupacionais ou de dano ao meio ambiente. Neste caso, o tratamento é externo/terceirizado, devendo ser observadas as condições de segurança para o transporte entre o estabelecimento gerador e o local do tratamento. O gerador dos resíduos é o responsável por contratar e monitorar a empresa e verificar se o sistema para tratamento de RSS que ela adota tem licenciamento ambiental, de acordo com a Resolução Conama no 237/97 (BRASIL, 1997), e da Vigilância Sanitária (SÃO PAULO, 1998), pois as empresas que tratam resíduos também são fiscalizadas e controladas por esses órgãos.

\section{3) Disposição final}

Consiste na disposição de resíduos em solo previamente preparado para a sua recepção, obedecendo a critérios técnicos de construção e operação, com licenciamento ambiental.

\section{Tipos de aterros:}

- Aterro sanitário: técnica de destinação final de resíduos sólidos urbanos no solo, por meio de confinamento em camadas cobertas com material inerte, segundo normas específicas, de modo a evitar danos ou riscos à saúde e à segurança, minimizando os impactos ambientais (Figura 3).

- Aterro sanitário p/ resíduos perigosos classe I: utilizado para a disposição de resíduos sólidos no solo de forma segura e controlada, garantindo a preservação ambiental e a saúde pública. Consiste na compactação dos resíduos em camada sobre o solo devidamente impermeabilizado e no controle dos efluentes líquidos e de emissões gasosas. Seu recobrimento é feito diariamente com camada de solo, compactada com espessura de $20 \mathrm{~cm}$, para evitar o aparecimento de roedores, moscas e baratas, espalhamento de papéis e lixo pelos arredores e poluição das águas superficiais e subterrâneas (Figura 4). Ex.: resíduos perigosos de medicamentos 
como drogas antineoplásicas constantes no Anexo II da Portaria CVS nº 21/08 e RDC Anvisa n 222/18.

\section{Gestão de resíduos na produção animal}

Na produção animal, o manejo zoosanitário também requer cuidados particulares quanto à geração e à gestão de resíduos utilizados na profilaxia animal, como vacinas, antimicrobianos e outros medicamentos. Os RSS devem ser tratados conforme já mencionado, assim como outros resíduos que devem ser destinados de maneira ambientalmente adequada, pois, como em outros nichos de produção, os produtos de origem animal terão pela frente o desafio de serem produzidos de forma limpa, ou seja, sem causar impacto ambiental. Portanto, os profissionais que atuam na área deverão ter foco e conhecimento para mitigar os impactos ambientais gerados pela forma de produção, além das metas de lucro. Ou seja, deverão trabalhar sob a ótica do desenvolvimento sustentável, buscando sempre o equilíbrio nos seus três pilares: ambiental, social e econômico (CONSELHO FEDERAL DE MEDICINA VETERINÁRIA, 2016).

Os profissionais da Medicina Veterinária e Zootecnia deverão considerar o manejo de resíduos no custo da matriz de produção, com a utilização dos preceitos de redução, reutilização e reciclagem, tanto para aprovação dos projetos agropecuários nos fóruns de homologação das licenças ambientais ou outorga do uso da água, como para o bom funcionamento das atividades em geral.

Os principais resíduos gerados nas atividades agrossilvipastoris podem ser classificados como orgânicos e inorgânicos. A maior geração de resíduos orgânicos na produção animal está relacionada a restos de alimentos, cama de frango, carcaças de animais mortos e restos de parição, além dos rejeitos das culturas, dos efluentes e dos resíduos produzidos nas agroindústrias, como abatedouros, laticínios e graxarias. Já os resíduos sólidos inorgânicos abrangem as embalagens produzidas nos segmentos de agrotóxicos, fertilizantes e insumos

\section{CONSELHO REGIONAL DE MEDICINA VETERINÁRIA DO ESTADO DE SÃO PAULO Comissão de Saúde Ambiental}

\section{DESTINAÇĀO ADEQUADA DOS RESIDUOS DE SERVIÇOS DE SAÚDE ANIMAL}
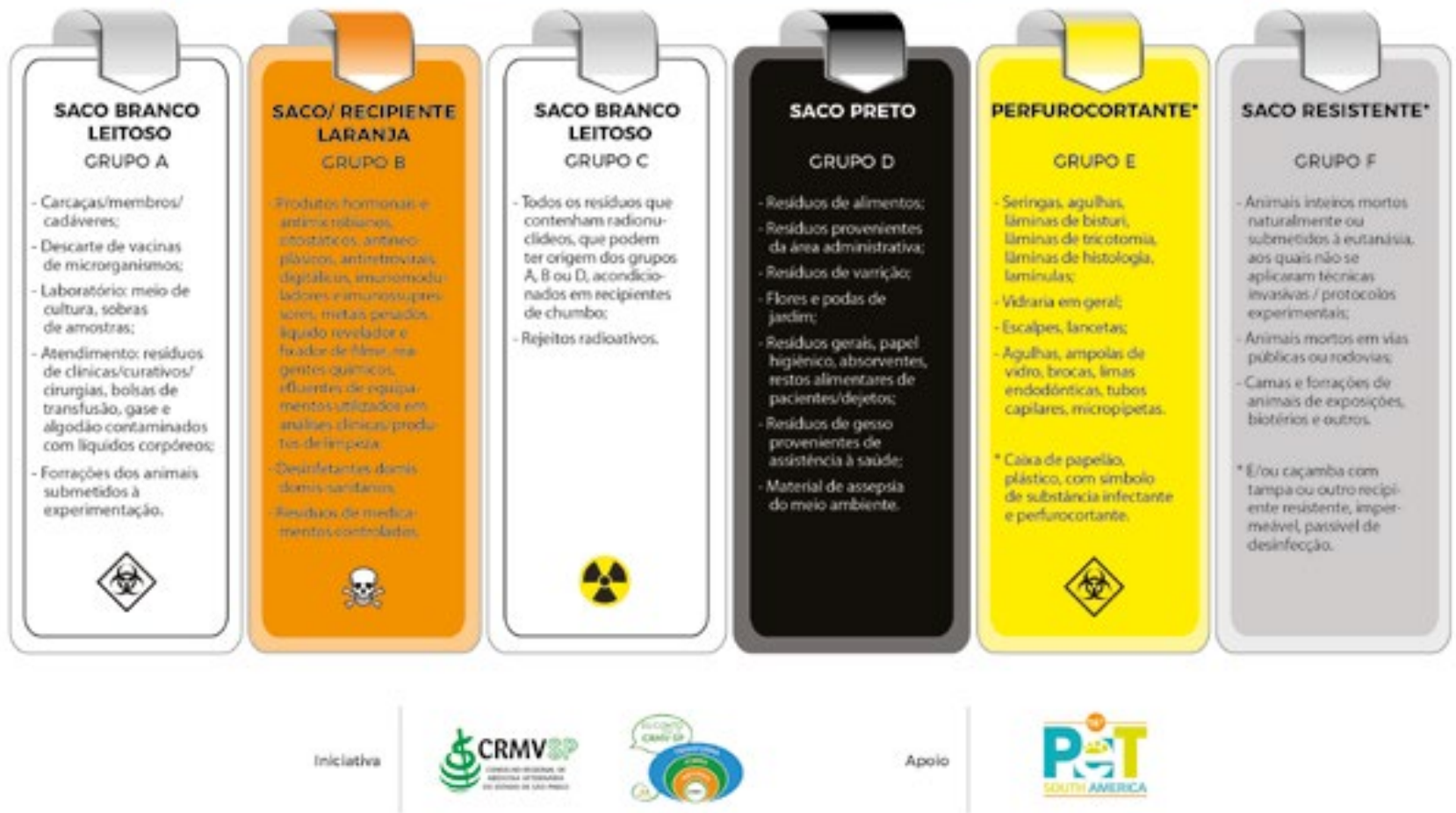

Figura 2 - Classificação dos resíduos de acordo com RDC n³06/04 e Res. Conj. SS/SMS/SJDC-SP n¹/04.

Fonte: Conselho Regional de Medicina Veterinária do Estado de São Paulo (2016). 


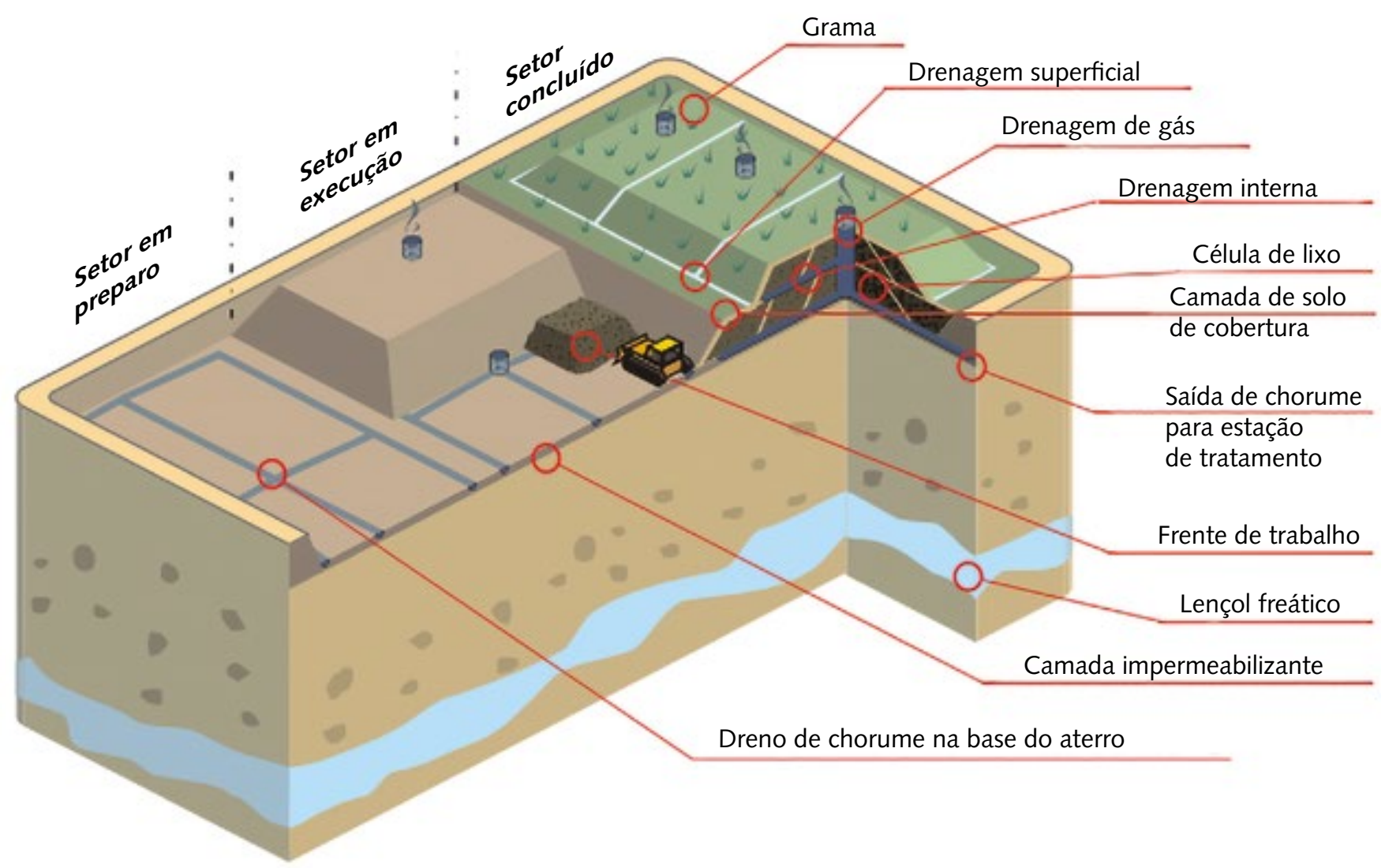

Figura 3 - Corte da seção de aterro sanitário.

Fonte: Website Resíduos Sólidas da SEMARH-AL. ${ }^{(3)}$

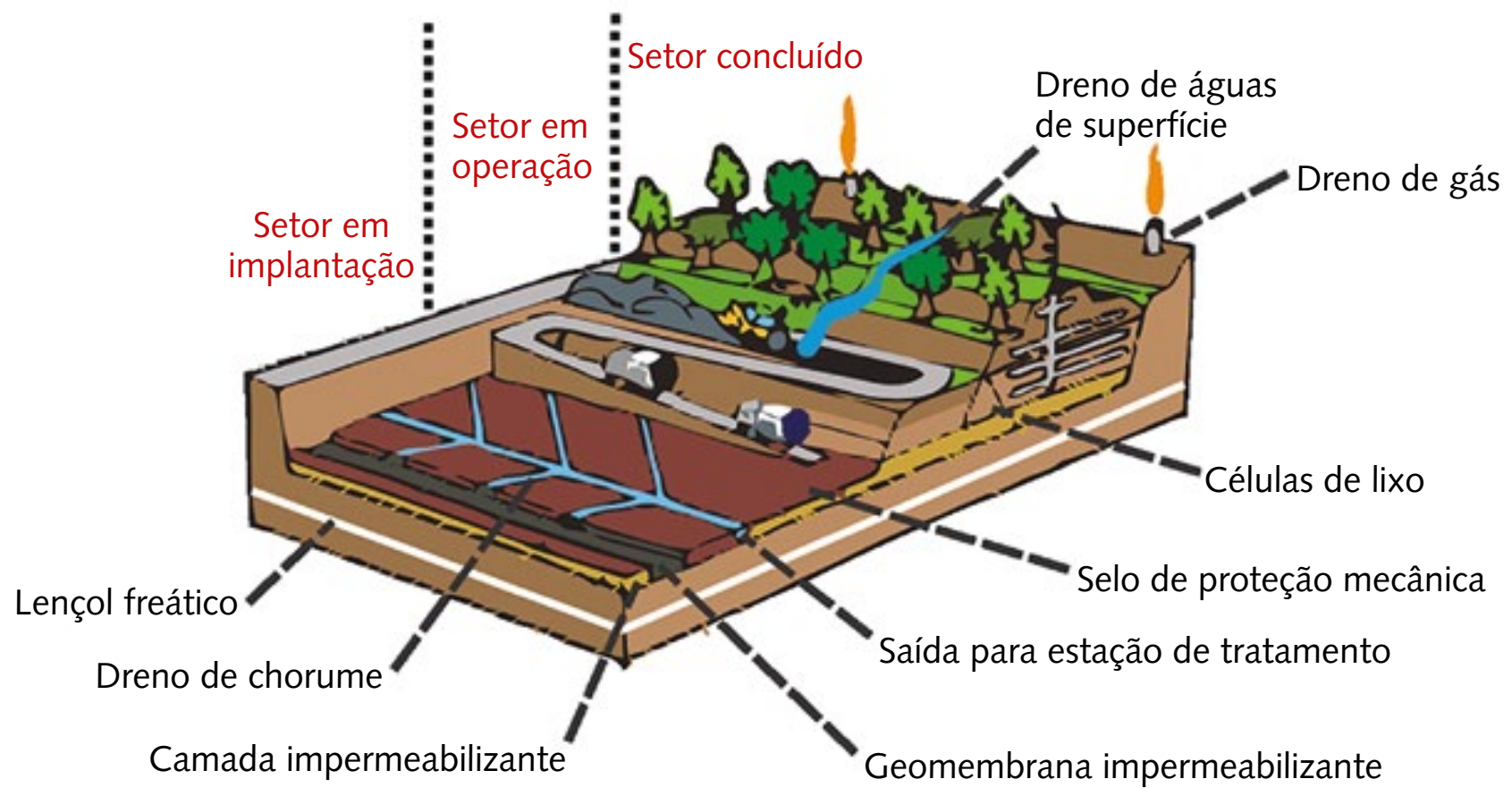

Figura 4 - Aterro de resíduos perigosos classe 1, aterro industrial.

Fonte: Website Resíduos Sólidas da SEMARH-AL. ${ }^{(4)}$

\footnotetext{
(3) Disponível em: <https://bit.ly/2DvftEl>. Acesso em: 2 ago. 2018.

(4) Disponível em: <https://bit.ly/2zEcW6l>. Acesso em: 25 mar. 2018.
} 
farmacêuticos veterinários, além dos resíduos sólidos domésticos da área rural (CRMV-MG, 2013).

O gerenciamento dos resíduos orgânicos está vinculado ao tipo de manejo e, sempre que possível, deverá buscar formas de reaproveitamento como compostagem, uso de esterqueiras ou bioesterqueiras e biodigestores com geração de energia limpa, barata e renovável, além de redução do impacto ambiental e de gastos com eletricidade, esgoto e descarte de resíduos.

Quanto ao gerenciamento dos resíduos inorgânicos, as experiências positivas de logística reversa das embalagens vazias de agrotóxicos podem servir de modelo para os demais segmentos, que ainda carecem de políticas específicas para a destinação ambientalmente correta dos resíduos gerados. Neste sentido, o PGRS é um dos instrumentos pelo qual o médico-veterinário e/ou zootecnista atende a PNRS aprovada pela Lei Federal no $12.305 / 10$ (BRASIL, 2010), e deve conter:

1) descrição do empreendimento ou atividade;

2) diagnóstico dos resíduos sólidos gerados ou administrados, contendo origem, volume e caracterização dos resíduos, incluindo os passivos ambientais a eles relacionados;

3) observação das normas estabelecidas pelos órgãos do Sistema Nacional do Meio Ambiente (Sisnama), do Sistema Nacional de Vigilância Sanitária (SNVS) e do Sistema Unificado de Atenção à Sanidade Agropecuária (Suasa) e, se houver, o plano municipal de gestão integrada de resíduos sólidos com:

a) explicitação dos responsáveis pelas diferentes etapas do gerenciamento de resíduos sólidos;

b) definição dos procedimentos operacionais relativos às etapas do gerenciamento de resíduos sólidos sob responsabilidade do gerador;

4) identificação das soluções consorciadas ou compartilhadas com outros geradores;

5) ações preventivas e corretivas a serem executadas em situações de gerenciamento incorreto ou acidentes;

6) metas e procedimentos relacionados à minimização da geração de resíduos sólidos e à observação das normas do Sisnama, do SNVS e do Suasa, à reutilização e reciclagem;

7) se couber, ações relativas à responsabilidade compartilhada pelo ciclo de vida dos produtos;
8) medidas saneadoras dos passivos ambientais relacionados aos resíduos sólidos;

9) periodicidade de sua revisão, observando, se couber, o prazo de vigência da respectiva licença de operação a cargo dos órgãos do Sisnama.

Convém ressaltar que o PGRS deverá atender ao disposto no plano municipal de gestão integrada de resíduos sólidos do município em que se encontra a propriedade, sem prejuízo das normas estabelecidas pelos órgãos do Sisnama, do SNVS e do Suasa. A inexistência do plano municipal de gestão integrada de resíduos sólidos não obsta a elaboração, implementação ou operacionalização do PGRS.

\section{Considerações finais}

$\mathrm{O}$ atual crescimento populacional tem determinado a necessidade de maior produção de alimentos por meio de atividades como a agricultura e a pecuária, que geram grandes volumes de resíduos de difícil tratamento e disposição final, sobretudo após a aprovação da Lei Federal $n^{\circ} 12.305 / 10$ (BRASIL, 2010), que instituiu a PNRS, que estabelece princípios, objetivos, diretrizes e responsabilidades dos geradores de resíduos e do poder público, dispondo também sobre as formas adequadas de sua destinação.

Órgãos como a Anvisa e o Conama têm assumido o papel de orientação, estabelecimento de regras e regulamentação da conduta dos diferentes agentes que geram resíduos, em especial os serviços de saúde. Dentre os vários pontos importantes das resoluções da Anvisa (RDC no 222/18) e do Conama (Resolução no 358/05) destacam-se:

- a responsabilidade dos geradores pelo gerenciamento dos resíduos vai até a sua disposição final;

- a necessidade/exigência de se fazer a segregação na fonte;

- a orientação para tratar a fração dos resíduos que realmente necessitam de tratamento;

- a possibilidade de solução diferenciada para a disposição final, desde que aprovada pelos órgãos de meio ambiente, limpeza urbana e de saúde;

- a possibilidade de a empresa contratar/terceirizar os serviços de elaboração, implantação e monitoramento do PGRSS.

$\mathrm{Na}$ agropecuária também estão ocorrendo mudanças e adaptações para atendimento da legislação ambiental, e há experiências bem-sucedidas de destinação adequada de resíduos de embalagens de defensivos agrícolas 
(INSTITUTO NACIONAL DO PROCESSAMENTO DE EMBALAGENS VAZIAS, 2011), que podem ser adaptadas para os medicamentos utilizados na atenção à saúde animal. A aquisição desses medicamentos deverá estar atrelada ao recolhimento das embalagens primárias de vacinas, medicamentos vencidos ou de restos que não serão mais utilizados, de modo a ser cumprido o que é chamado de logística reversa, contemplada na Legislação Ambiental e Sanitária.

Outro problema ambiental que requer solução é a disposição final ambientalmente adequada de cadáveres de animais, que tem na compostagem, dentre outras possibilidades, a disposição adequada, porém ainda pouco utilizada na prática.

Convém ressaltar que o Ministério da Agricultura, Pecuária e Abastecimento (BRASIL, 2018a), órgão com atribuições diversas junto à agropecuária, prepara uma normatização para regulamentar o recolhimento, transporte, armazenagem, manuseio, transformação e eliminação de animais mortos, porém não abatidos, inclusive contemplando o registro de estabelecimentos/ unidades de beneficiamento de produtos não comestíveis, de compostagem e de transformação que processem de forma segura esses animais, com o objetivo de prevenir e minimizar os riscos para a saúde pública, animal e do meio ambiente, além de possibilitar uma destinação sustentável e com segurança sanitária.

Devido à complexidade e importância do tema para a área animal, o CRMV-SP criou a Comissão de Saúde Ambiental (CSA), que tem trabalhado no sentido de instrumentalizar os profissionais da Medicina Veterinária e da Zootecnia com material que os auxilie para o atendimento da legislação sanitária e ambiental, de modo a exercer serviços com qualidade, considerando a preservação da saúde humana, animal e ambiental, ou seja, a saúde única.

A CSA/CRMV-SP criou um adesivo com os grupos de resíduos (Figura 2) contemplados pela legislação e o disponibilizou a todos os profissionais do Estado, produziu o PGRSSA simplificado e de fácil entendimento e tem realizado orientações específicas em oficinas que tratam da gestão de resíduos. (-)

\section{Referências}

BRASIL. Lei $\mathrm{n}^{\circ}$ 12.305, de 2 de agosto de 2010. Institui a Política Nacional de Resíduos Sólidos; altera a Lei no 9.605, de 12 de fevereiro de 1998; e dá outras providências. Diário Oficial da União, Poder Executivo, Brasília, DF, 3 ago. 2010.

BRASIL. Ministério da Agricultura, Pecuária e Abastecimento. Secretaria de Defesa Agropecuária. Portaria n³7, de 17 de abril de 2018. Diário Oficial da União, Brasília, DF, 19 abr. 2018a. Seção 1, p. 11.

BRASIL. Ministério da Saúde. Agência Nacional de Vigilância Sanitária. Manual de gerenciamento de resíduos de serviços de saúde. Brasília, DF: Ministério da Saúde, 2006. 182 p.

BRASIL. Ministério da Saúde. Agência Nacional de Vigilância Sanitária. Resolução da Diretoria Colegiada $n^{\circ} 222$, de 28 de março de 2018. Diário Oficial da União, Brasília, DF, 29 mar. 2018b.

BRASIL. Ministério da Saúde. Agência Nacional de Vigilância Sanitária. Resolução da Diretoria Colegiada n 306 de 7 de dezembro de 2004. Diário Oficial da União, Brasília, DF, 8 dez. 2004.

BRASIL. Ministério do Meio Ambiente. Conselho Nacional de Meio Ambiente. Resolução Conama n 237, de 19 de dezembro de 1997. Diário Oficial da União, Brasília, DF, 20 dez. 1997.

BRASIL. Ministério do Meio Ambiente. Conselho Nacional de Meio Ambiente. Resolução Conama n 358, de 29 de abril de 2005. Diário Oficial da União, Brasília, DF, 4 mai. 2005. Seção 1, p. 63-65.

CONSELHO FEDERAL DE MEDICINA VETERINÁRIA. Comissão Nacional de Meio Ambiente: objetivos de desenvolvimento sustentável e sua relação com a Saúde Única. Revista CFMV, Brasília, DF, n. 71, p. 8-10, out./dez, 2016.

CONSELHO REGIONAL DE MEDICINA VETERINÁRIA DO ESTADO DE SÃO PAULO. Comissão de Saúde Ambiental. Manual de responsabilidade técnica e legislação: gestão de resíduos e meio ambiente. São Paulo, 2018.

CONSELHO REGIONAL DE MEDICINA VETERINÁRIA DO ESTADO DE SÃO PAULO. Comissão de Saúde Ambiental. Plano de Gerenciamento de Resíduos de Serviços de Saúde Animal (PGRSSA). São Paulo, 2015.

CORREA, L. B. et al. O saber resíduos sólidos de serviços de saúde na formação acadêmica: uma contribuição da educação ambiental. Interface, Botucatu; v. 9, n. 18, p. 571-584, set./dez. 2005.

FUNDAÇÃO DE ESTUDO E PESQUISA EM MEDICINA VETERINÁRIA E ZOOTECNIA. Saneamento ambiental: gerenciamento de resíduos sólidos. Belo Horizonte, 2013. (Cadernos Técnicos de Veterinária e Zootecnia, 68).

INSTITUTO NACIONAL DO PROCESSAMENTO DE EMBALAGENS VAZIAS. Relatório de sustentabilidade 2011. São Paulo, 2011.

SÃO PAULO (Estado). Lei n 10.083, de 23 de setembro de 1998. Dispõe sobre o Código Sanitário do Estado. Diário Oficial, Poder Executivo, São Paulo, 24 set. 1998.

SÃO PAULO (Estado). Secretaria de Estado da Saúde. Coordenadoria de Controle de Doenças. Centro de Vigilância Sanitária. Divisão Técnica de Ações sobre Meio Ambiente. Portaria CVS $n^{\circ} 21$, de 10 de setembro de 2008. Diário Oficial, Poder Executivo, São Paulo, 11 set. 2008. 
SÃO PAULO (Estado). Secretaria de Estado da Saúde. Resolução Conjunta $n^{\circ}$ SS/SMA/SJDC-SP-1, de 15 de julho de 2004. Estabelece classificação, as diretrizes básicas e o regulamento técnico sobre Resíduos de Serviços de Saúde Animal - R.S.S.A. Diário Oficial, Poder Executivo, São Paulo, 16 jul. 2004.

SILVA, C. D. Diagnóstico do gerenciamento dos resíduos sólidos de serviços de saúde nos estabelecimentos veterinários de
Mossoró-RN. 2014. 87 f. Dissertação (Mestrado em Ambiente, Tecnologia e Sociedade) - Universidade Federal Rural do SemiÁrido, Mossoró, 2014.

SISSINO, C. L. S.; MOREIRA, J. C. Ecoeficiência: um instrumento para a redução da geração de resíduos e desperdícios em estabelecimentos de saúde. Cadernos de Saúde Pública, Rio de Janeiro, v. 21, n. 6, p. 1893-1900, 2005. 